Sally-Ann Colbert MB FFA, Deirdre M. OHanlon MB FRCSI, * Fidelma Flanagan MB FFR, ${ }^{\dagger}$ Rory Page MB FFA, Denis C. Moriarty MD FFA

\section{The laryngeal mask airway reduces blood flow in the common carotid artery bulb}

Purpose: The introduction of the laryngeal mask airway (LMA) has had a major impact on anaesthetic practice in the last ten years. Previous authors have demonstrated pressures equivalent to mean arterial blood pressure within the cuff of the LMA. This study examined the effects of cuff inflation on the cross sectional area, flow and velocity of blood flow at the level of the carotid sinus.

Methods: Seventeen patients scheduled to have LMAs inserted as part of routine anaesthetic management were recruited into the study. Measurements of the common carotid artery bulb area, peak velocity and blood flow were performed upon LMA cuff inflation and deflation using a $5 \mathrm{MHz}$ pulse wave Doppler probe.

Results: Deflation of the cuff resulted in an increase in the cross sectional area (from $0.58 \pm 0.05$ to $0.64 \pm$ $0.04 \mathrm{~cm}^{2} ; P<0.005$ ), an increase in blood flow (from $65.6 \pm 5.6$ to $73.9 \pm 5.6 \mathrm{~cm}^{3} \cdot \mathrm{sec}^{-1} ; P<0.05$ ) and a slight but non significant increase in velocity of blood flow.

Conclusion: This study demonstrates that inflation of the cuff on the LMA results in a decrease in carotid bulb cross sectional area which results in a decrease in blood flow.

Objectif : Au cours des dix dernières années, l'introduction du masque laryngé (ML) a eu un impact considérable sur la pratique de l'anesthésie. Certains auteurs ont déjà démontré des valeurs de pression interne de la manchette du ML équivalentes à la pression artérielle moyenne. Cette étude examine les effets de l'insufflation de la manchette sur la surface transversale du sinus carotidien et sur le débit et la vélocité du sang à ce niveau.

Méthodes : Dix-sept patients programmés pour l'insertion d'un ML au cours d'une anesthésie normale ont participé à l'étude. Des mesures avec une sonde Doppler utilisant une onde pulsée de $5 \mathrm{MHz}$ de la surface du bulbe carotidien, de la vélocité de pointe et du débit sanguin ont été effectuées au moment du gonflement et du dégonflement de la manchette.

Résultats : Le dégonflement de la manchette a provoqué une augmentation de la surface sagittale (de $0,58 \pm$ 0,05 à $0,64 \pm 0,04 \mathrm{~cm}^{2} ; P<0,005$ ), une augmentation du débit sanguin (de $65,6 \pm 5,6$ à $73,9 \pm 0,56 \mathrm{~cm}^{3} \cdot \mathrm{s}^{-1} ;$ $P<0,05$ ) et une légère augmentation non significative de la vélocité du flot sanguin.

Conclusion : Cette étude montre que le gonflement de la manchette du ML produit une baisse de la surface transversale du bulbe carotidien et une baisse du débit sanguin.

From the Departments of Anaesthesia, Radiology ${ }^{\dagger}$ and Surgery, ${ }^{\star}$ The Mater Misericordiac Hospital, Eccles Street, Dublin 7, Ireland. Address correspondence to: Dr. S. Colbert, Department of Anaesthesia, St. James Hospital, James Street, Dublin 8, Ireland; Phone 353-01-4537941.

Accepted for publication October 3, 1997. 
$\mathrm{T}$

HE laryngeal mask airway (LMA) has had a major impact on anaesthetic practice since its introduction in $1983 .{ }^{1}$ In addition to providing a valuable alternative to tracheal intubation, advantages include ease of insertion and the benefit of a secure airway in patients with a potentially difficult intubation. ${ }^{2-4}$

When correctly placed, the tip of the LMA cuff lies at the base of the hypopharynx against the upper oesophageal sphincter. The sides lie in the pyriform fossae, and the upper border of the mask lies at the base of the tongue pushing it forward. ${ }^{5}$ When the cuff of the LMA is inflated, a bulging of the tissues overlying the larynx is clearly visible in many patients. This indicates that the LMA is in position. The protrusion results because the LMA cuff generates a pressure against the adjacent pharynx sufficient to displace the thyroid and the cricoid cartilages anteriorly as the cuff is squeezed out of the triangular shaped base of the hypopharynx..$^{6,7} \mathrm{~A}$ recent study by Nandwani et al. demonstrated that, on full inflation, of the LMA cuff there was an anterior displacement of the larynx of $0.8 \mathrm{~cm}$ with a range from $0.6-1.1 \mathrm{~cm} .{ }^{8}$

The larynx extends from the root of the tongue to the trachea. In the male adult it is situated opposite the third to sixth cervical vertebrae but occupies a higher position in the child and in the adult female. The carotid artery passes obliquely upwards from the sternoclavicular joint to the level of the upper border of the thyroid cartilage where it divides into the external and internal carotid arteries. The carotid sinus, a slight dilatation of the vessel is found at this point. The tunica media is thinner than elsewhere and the tunica adventitia contains a large number of sensory nerve endings in the carotid sinus. ${ }^{9}$ The anterior displacement which characteristically follows cuff inflation on the LMA may also result in lateral displacement of adjacent structures including the structures within the carotid sheath. We have previously demonstrated that inflation of the cuff results in a decreased area in the carotid artery bulb. ${ }^{10}$ This study was established to examine the effect of the LMA on the carotid artery in a larger group of patients undergoing elective surgery.

\section{Materials and methods}

Following Ethics Committee approval informed consent was obtained from 17, ASA 1-3 patients undergoing elective cystoscopy. All patients were scheduled to have an LMA inserted as part of routine anaesthetic management. Premedication consisted of $10 \mathrm{mg}$ of diazepam po. Anaesthesia was induced with $2-3 \mathrm{mg} \cdot \mathrm{kg}^{-1}$ propofol followed by $1.5 \mu \mathrm{g} \cdot \mathrm{kg}^{-1}$ fentanyl. An appropriately sized LMA was inserted in a standard fashion by one operator in accordance with the maker's recommendations and the cuff was inflated (Colgate Medical Ltd., Winsor, UK). All patients breathed spontaneously, anaesthesia being maintained with oxygen $40 \%$, nitrous oxide $60 \%$ and isoflurane. The isoflurane was adjusted to maintain arterial pressure and heart rate within $20 \%$ of baseline values. All patients had a clinically clear airway and a normal capnogram pattern during the procedure. The surgery proceeded uneventfully in all the patients.

At the end of surgery a $5 \mathrm{MHz}$ pulse wave Doppler probe was applied by one operator to the neck and a slow two dimensional transverse scan was performed from the lowest portion of the neck to a point $4-6 \mathrm{~cm}$ above the bifurcation of the common carotid with the head maintained in the neutral position. The transducer was rotated longitudinally for measurement of Doppler spectral waveforms. Using the $2 \mathrm{D}$ real time ultrasound images, the junction at the extreme uppermost part of the common carotid and the carotid bulb was selected for the site of all measurements as it was easily identified and reproducible. The position was confirmed by identifying the characteristic waveform pattern. A transverse $2 \mathrm{D}$ real time scan was then obtained at right angles to the vessel. The sonographic morphology of the carotid wall was easily seen and a region of interest was drawn around the circumference of the vessel. The cross sectional area was computed by built-in software and displayed on the monitor. The pulsed-Doppler waveform pattern demonstrates an initial systolic peak with persistent high levels of diastolic flow throughout the cycle. Arterial velocity can be measured by converting the frequency shift information contained in the Doppler waveform into velocity information. The peak blood flow is derived from the cross-sectional area and the peak velocity.

The cuff on the LMA was fully deflated prior to performing any measurements. The cuff on the LMA was then inflated with a volume of air in accordance with manufacturers instructions. Size \#3 LMAs were inflated with $20 \mathrm{ml}$ room air and size \#4 LMAs were inflated with $30 \mathrm{ml}$. Measurements of the common carotid artery bulb area, the peak velocity and the blood flow within the carotid sinus were made as follows: i) right carotid with LMA cuff inflated, ii) right carotid with cuff deflated, iii) left carotid with cuff inflated, and iv) left carotid with cuff deflated. The measurements were performed in triplicate during mid expiration and the results averaged. The mean systemic blood pressure, heart rate and $\mathrm{P}_{\mathrm{ET}} \mathrm{CO}_{2}$ remained within $10 \%$ of their resting values during these manoeuvres. 
A proforma was completed on all patients detailing demographic features, intra-operative events and the measurements recorded at the end of the procedure. Statistical analysis was performed using the Wilcoxon signed-rank test, Mann Whitney U, Spearman's test with significance assumed at the $5 \%$ level.

\section{Results}

Seventeen patients, nine men and eight women, were recruited into the study. The mean \pm SEM age was $49 \pm 3.7 \mathrm{yr}$. A \#3 LMA was inserted in the women and \#4 LMA in the men. There were 34 sets of results available for analysis.

There were increases in area and blood flow following deflation of the cuff. No difference was observed in velocity (Table I). The variables were compared with the cuff inflated and deflated. There were correlations between

TABLE I Changes in arca, velocity and flow following cuff inflation.

\begin{tabular}{llll}
\hline & Inflated & Deflated & $P$ \\
\hline Area $\left(\mathrm{cm}^{2}\right)$ & $0.58 \pm 0.05$ & $0.64 \pm 0.04$ & $<0.005$ \\
Flow $\left(\mathrm{cm}^{3} \mathrm{sec}^{-1}\right)$ & $65.6 \pm 5.6$ & $73.9 \pm 5.6$ & $<0.05$ \\
Velocity $\left(\mathrm{cm} \mathrm{sec}^{-1}\right)$ & $114.6 \pm 5.4$ & $118.4 \pm 5.9$ & NS \\
\hline
\end{tabular}

Mean \pm SEM.

TABLE II Comparison of \#3 LMA (female, $20 \mathrm{ml}$ air) and \#4 LMA (male, $30 \mathrm{ml}$ air).

\begin{tabular}{|c|c|c|c|}
\hline & $L M A \# 3$ & $L M A \# 4$ & $P$ \\
\hline Age (yr) & $48.8 \pm 6.4$ & $49.2 \pm 4.2$ & NS \\
\hline Area - inflated $\left(\mathrm{cm}^{2}\right)$ & $0.52 \pm 0.05$ & $0.63 \pm 0.08$ & NS \\
\hline Area - deflated $\left(\mathrm{cm}^{2}\right)$ & $0.58 \pm 0.05$ & $0.69 \pm 0.07$ & NS \\
\hline Flow - inflated $\left(\mathrm{cm}^{3} \cdot \mathrm{sec}^{-1}\right)$ & $63.3 \pm 9.1$ & $67.6 \pm 7.0$ & NS \\
\hline Flow - deflated $\left(\mathrm{cm}^{3} \cdot \mathrm{sec}^{-1}\right)$ & $66.2 \pm 7.2$ & $80.8 \pm 8.4$ & NS \\
\hline Velocity - inflated $\left(\mathrm{cm} \cdot \mathrm{sec}^{-1}\right)$ & $119.7 \pm 10.3$ & $110.0 \pm 4.9$ & NS \\
\hline Velocity - deflated $\left(\mathrm{cm} \cdot \mathrm{sec}^{-1}\right)$ & $115.2 \pm 9.7$ & $121.2 \pm 7.6$ & NS \\
\hline$\%$ change area (\%) & $+11.5 \pm 2.8$ & $+9.5 \pm 4.9$ & NS \\
\hline$\%$ change flow (\%) & $+4.6 \pm 6.6$ & $+19.5 \pm 6.2$ & NS \\
\hline$\%$ change velocity (\%) & $-3.7 \pm 6.9$ & $+10.2 \pm 5.5$ & NS \\
\hline
\end{tabular}

Mean \pm SEM the area $(\mathrm{r}=0.8308 ; P<0.001)$, flow $(\mathrm{r}=0.6675$; $P<0.001)$ and velocity $(r=0.5645 ; P<0.001)$ observed when measurements were performed with the cuff inflated and deflated. There was a positive correlation between age and area with the cuff inflated $(\mathrm{r}=0.6469 ; P<0.001)$ and the cuff deflated $(\mathrm{r}=0.7162 ; P<0.001)$ between age and flow with the cuff inflated $(r=0.5358 ; P=0.001)$ and the cuff deflated $(\mathrm{r}=0.4274 ; P=0.012)$. There was no correlation between age and velocity.

When the patients were divided according to size of LMA (and consequently sex and the amount of air insufflated) no differences were observed between groups (Table II). The patients were also divided according to age. Five patients were over $60 \mathrm{yr}$ and ten measurements were available for analysis. The measurements obtained in this group were compared with those obtained in the under 60 year age group (12 patients; 24 measurements) (Table III).

Patients were divided according to the presence or absence of atheromatous disease on initial ultrasound. Three patients had evidence of atheromatous disease (two male and one female) which was bilateral and six sets of measurements were available for analysis. Patients with atheromatous disease were older, had a larger carotid sinus cross sectional area and a higher blood flow (Table IV). There were no changes in velocity observed between these groups.

\section{Discussion}

In this prospective study examining the effects of inflation of the LMA cuff on the carotid artery, decreases were observed in both cross sectional area and flow in the carotid sinus. In a previous case report from this unit, an increase in cross sectional area was also observed following cuff deflation. ${ }^{10}$ This patient was not included in the present study.

One previous study examining the effects of LMA cuff inflation on the position of adjacent structures in the neck demonstrated anterior displacement of the

TABLE III Groups divided by age, $<$ and $>60 \mathrm{yr}$.

\begin{tabular}{llll}
\hline & $<60$ & $>60$ & $P$ \\
\hline n & $12(24$ measurements $)$ & $5(10$ measurements $)$ & \\
Area - inflated $\left(\mathrm{cm}^{2}\right)$ & $0.48 \pm 0.03$ & $0.32 \pm 0.1$ & $P<0.0001$ \\
Area - deflated $\left(\mathrm{cm}^{2}\right)$ & $0.53 \pm 0.03$ & $0.90 \pm 0.09$ & $P<0.001$ \\
Flow - inflated $\left(\mathrm{cm}^{3} \cdot \mathrm{sec}^{-1}\right)$ & $53.7 \pm 3.7$ & $94.1 \pm 13.4$ & $\mathrm{P}<0.01$ \\
Flow - deflated $\left(\mathrm{cm}^{3} \cdot \mathrm{sec}^{-1}\right)$ & $62.4 \pm 3.7$ & $101.5 \pm 13.8$ & $\mathrm{P}<0.01$ \\
Velocity - inflated $\left(\mathrm{cm}^{\left.-\mathrm{sec}^{-1}\right)}\right.$ & $116.5 \pm 6.8$ & $119.9 \pm 10.0$ & $\mathrm{NS}$ \\
Velocity - deflated $\left(\mathrm{cm} \cdot \mathrm{sec}^{-1}\right)$ & $120.8 \pm 7.9$ & $112.4 \pm 7.5$ & $\mathrm{NS}$ \\
Percent change area & $10.9 \pm 3.6$ & $-7.4 \pm 6.6$ & $\mathrm{NS}$ \\
Percent change flow & $-9.5 \pm 5.9$ & $-5.5 \pm 4.7$ & $\mathrm{NS}$ \\
Percent change velocity & $+2.2 \pm 5.7$ & $-1.2 \pm 6.8$ & $\mathrm{NS}$ \\
\hline
\end{tabular}

Mean \pm SEM. 
TABLE IV Comparing variables in patients with and without atherosclerosis

\begin{tabular}{lccc}
\hline & $\begin{array}{c}\text { No atherosclerosis } \\
14(28 \text { measurements) }\end{array}$ & $\begin{array}{c}\text { Atherosclerosis } \\
3(6 \text { meastrements) }\end{array}$ & $P$ \\
\hline Age yr & $43.6 \pm 3.7$ & $74.3 \pm 1.2$ & 0.001 \\
Area - inflated $\left(\mathrm{cm}^{2}\right)$ & $0.49 \pm 0.03$ & $1.02 \pm 0.12$ & $<.0005$ \\
Area - deflated $\left(\mathrm{cm}^{2}\right)$ & $0.54 \pm 0.02$ & $1.09 \pm 0.07$ & 0.0001 \\
Flow - inflated $\left(\mathrm{cm}^{3} \cdot \mathrm{sec}\right)$ & $55.0 \pm 3.5$ & $114.9 \pm 16.8$ & $<.005$ \\
Flow - deflated $\left(\mathrm{cm}^{3} \cdot \mathrm{sec}\right)$ & $63.5 \pm 3.3$ & $114.2 \pm 16.1$ & $<.005$ \\
Velocity - inflated $(\mathrm{cm} \cdot \mathrm{sec})$ & $114.6 \pm 5.8$ & $110.3 \pm 12.6$ & $\mathrm{NS}$ \\
Velocity - deflated $(\mathrm{cm} \cdot \mathrm{sec})$ & $120.1 \pm 6.8$ & $+6.9 \pm 6.0$ & $\mathrm{NS}$ \\
Percent change arca & $+10.2 \pm 3.3$ & $+6.8 \pm 8.7$ & $\mathrm{NS}$ \\
Percent change flow & $+15.5 \pm 5.2$ & $-3.4 \pm 10.4$ & NS \\
Percent change velocity & $+4.8 \pm 5.0$ & NS & \\
\hline
\end{tabular}

Mean + SEM.

larynx but failed to demonstrate lateral displacement of the internal jugular vein or the common carotid artery. ${ }^{8}$ The internal jugular vein lies lateral to the carotid artery and thus may not be affected by cuff inflation in the larynx. The lack of effect on the common carotid artery, in particular lack of compression, is at variance with the results from the present study. Nandwani et al. examined young patients under $<40$ $\mathrm{yr}$, while the mean age of patients in the present study was 49 and only six $(35 \%)$ were $<40 \mathrm{yr}$. In the present study a small difference was seen in the area of the carotid sinus. Nandwani et al. failed to provide data and the lack of effect may also have been due to the smaller numbers studied. In addition Nandwani $e t$ al. did not mention at what level the carotid was examined. From the pictures provided, we can surmise that the common carotid artery was studied. In the present study, the carotid sinus was located using the Doppler probe. The tunica media is thinner in the carotid sinus than elsewhere in the carotid artery and thus may be more responsive to both internal and external pressure. The lack of observed effects may also relate to the level at which the carotid artery was studied.

Marjot demonstrated that insufflation of a size \#3 LMA with $20 \mathrm{ml}$ air may result in pressures of up to $150 \mathrm{mmHg}$ and that insufflation of a size \#4 LMA with $30 \mathrm{ml}$ air may result in pressures of up to $160 \mathrm{mmHg} .{ }^{11}$ The pressure exerted by the cuff of the LMA approximates and may exceed mean arterial pressure in many patients. While the pressures within the LMA cuff were not measured in this series the manufacturers' guidelines for cuff inflation were followed. Marjots results suggest a mechanism for the effects on the common carotid sinus observed in this study. This is a potential problem given the close proximity of these structures. Other authors have demonstrated that further unintentional inflation of the cuff may occur following carbon dioxide or nitrous oxide diffusion into the cuff. ${ }^{12}$
In addition, warming of the air contained within the cuff may occur after insertion into the pharynx and these events may result in further cuff expansion and in greater intracuff pressure and, may, potentially result in greater compression of surrounding structures.

In the over $60 \mathrm{yr}$ age group, the cross sectional area of the carotid artery was larger with the cuff deflated than in the younger age group and while there was no difference in the velocity, the blood flow was also greater with the cuff deflated. Following cuff inflation, there was a greater reduction in area in the older than in the younger group, the mean velocity increased in the older group compared with a decrease in the younger age group, perhaps reflecting compensatory mechanisms. Similar changes were seen in the flow in both groups. Similar changes were observed in patients with atheromatous disease, except that the area of the carotid artery decreased only marginally following inflation of the LMA cuff, presumably reflecting rigidity of the arterial wall consequent upon the presence of plaque. In the elderly population and in patients with atheromatous plaques within the carotid vessels, it is undesirable to compromise blood flow further through the carotid vessels, which is possible with use of the LMA as demonstrated in the present study. If atheromatous plaques with platelet thrombi are already in situ within the carotid artery, cuff inflation could result in dislodgment of emboli which could lead to post-operative neurological defects.

Awareness of the potential risks associated with the LMA are important when this apparatus is being used. Monitoring cuff pressures and the use of pressure relief valves, which have been employed with endotracheal tubes, may be of benefit. ${ }^{13} \mathrm{~A}$ knowledge of the effects of the LMA on the carotid sinus cross sectional area and blood flow through the carotid sinus are important when using this apparatus to avoid potential problems. 
In conclusion, in this study, it has been demonstrated that inflation of the LMA cuff results in a decrease in cross sectional area and a decrease in blood flow in the common carotid bulb and this may have important clinical implications.

\section{References}

1 Brain AIJ. The laryngeal mask - a new concept in airway management. Br J Anaesth 1983; 55: 801-5.

2 Brain AIJ. Three cases of difficult intubation overcome by the laryngeal mask airway. Anaesthesia 1985; 40: 353-5.

3 Beveridge ME. Laryngeal mask anaesthesia for the repair of cleft palate. Anaesthesia 1989; 44: 656-7.

4 Maltby JR, Loken RG, Watson NC. The laryngeal mask airway: clinical appraisal in 250 patients. Can J Anaesth 1990; 37: 509-13.

5 Goudsouzian NG, Denman W, Cleveland R, Shorten G. Radiologic localization of the laryngeal mask airway in children. Anesthesiology 1992; 77: 1085-9.

6 Brain AIJ. Laryngeal mask and trauma to the uvula: reply (Letter). Anaesthesia 1989; 44: 1014-5.

7 Brimacombe JR, Brain AIJ, Berry AM. The laryngeal mask airway. Instruction manual, 3rd ed. Colgate Medical Limited, 1996.

8 Nandwani N, Fairfield MC, Krarup K, Thompson J. The effect of laryngeal mask airway insertion on the position of the internal jugular vein. Anaesthesia 1997; 52: 77-83.

9 Warwick $R$, Williams PL. Grays Anatomy, 35th ed. London: Longman Group Ltd, 1973.

10 Colbert SA, OHanlon D, Page R, Flannagan $F$, Moriarty $D C$. Haemodynamic changes with the laryngeal mask - off the cuff. Eur J Anaesth; 1997; 14: 514-7.

11 Marjot $A$. Pressure exerted by the laryngeal mask airway cuff upon the pharyngeal mucosa. $\mathrm{Br} J$ Anaesth 1993; 70: 25-9.

12 Lumb $A B$, Wrigley $M W$. The effect of nitrous oxide on laryngeal mask cuff pressure. Anaesthesia 1992; 47 : 320-3.

13 Stanley TH, Foote JL, Liu W-S. A simple pressure-relief valve to prevent increases in endotracheal tube cuff pressure and volume in intubated patients. Anesthesiology 1975; 43: 478-81. 